Cite this: Phys. Chem. Chem. Phys., 2014, 16, 9233

Received 4th March 2014, Accepted 3rd April 2014

DOI: $10.1039 / c 4 c p 00931 b$

www.rsc.org/pccp

\section{Parallel deposition of size-selected clusters: a novel technique for studying size-selectivity on the atomic scale $\uparrow$}

\author{
Yuan Luo, $\ddagger^{\mathrm{a}}$ Hyun Ook Seo, $\ddagger^{\mathrm{b}}$ Martin Beck, ${ }^{a}$ Sebastian Proch, ${ }^{a}$ Young Dok Kim*bc \\ and Gerd Ganteför*a
}

\begin{abstract}
A new size-selected cluster deposition technique referred to as "parallel-deposition" is presented. An ion beam of multi-sized $\mathrm{Au}_{n}$ clusters was spatially separated into individual cluster sizes by utilizing a Wien filter and the clusters spatially separated based on their atomic sizes were simultaneously deposited on a $\mathrm{SiO}_{2} / \mathrm{Si}(100)$ substrate. Parallel-deposited $\mathrm{Au}_{n}$ clusters ( $n=6,7$, and 8 ) on the $\mathrm{SiO}_{2} / \mathrm{Si}(100)$ substrate showed even-odd oxidation behaviour upon exposure to an atomic oxygen atmosphere, demonstrating the potential of this new technique to study the size-dependent properties of deposited clusters in various research fields.
\end{abstract}

The size-selectivity of transition metal nanoparticles has been extensively studied in many different research fields over the past few decades due to its importance in fundamental science as well as applications in energy and environmental sciences. ${ }^{1-13}$

Clusters are entities consisting of only several hundreds of atoms. In this very small size regime, changes in various physical and chemical properties as a function of the atoms in a cluster can be not only strongly size-dependent but also non-scalable. ${ }^{14-18}$ Only even-numbered anionic Au clusters consisting of less than 21 atoms in the gas phase react with molecular oxygen whereas the odd-numbered neighbors are inert, representing only one of the many recent examples of

\footnotetext{
${ }^{a}$ Department of Physics, University of Konstanz, D-78457 Konstanz, Germany. E-mail: gerd.gantefoer@uni-konstanz.de

${ }^{b}$ Department of Chemistry, Sungkyunkwan University, Suwon, 440-746, Korea. E-mail: ydkim91@skku.edu

${ }^{c}$ Biorefinery Research Group, Korea Republic Institute of Chemical Technology, Daejeon, 305-600, Republic of Korea

$\dagger$ Electronic supplementary information (ESI) available: Experimental set-up for the generation of the $(+)$-charged cluster ion beam is schematically shown. Wien filter mass spectrum of $\mathrm{Au}_{n}{ }^{+}$clusters obtained by scanning the magnetic field with a fixed electric field of $100 \mathrm{~V}$ is shown. The in situ XPS set-up used to determine the spatial separation of clusters spots after the parallel-deposition of $\mathrm{Au}_{n}$ clusters $(n=6,7$, and 8$)$ on the $\mathrm{SiO}_{2} / \mathrm{Si}$ surface is schematically shown. The experimental scheme used to determine the spatial resolution of X-ray photoelectron spectroscopy (XPS) with Au foil is displayed along with XPS spectra obtained at different $Z$ positions. See DOI: 10.1039/c4cp00931b

\$ These authors contributed equally to this work.
}

non-scalable changes in the properties of clusters as a function of the number of atoms in a cluster. ${ }^{18-23}$ It is worth noting that mass-selection of clusters on the atomic scale should be achieved for studying the size-selectivity of clusters, which can only be done with the aid of mass spectrometry. After the generation of variously sized clusters in the gas phase, the clusters are guided to pass through a mass spectrometer, in which clusters are timely or spatially separated by their cluster masses. ${ }^{24-26}$ The size-dependence of properties of free gas-phase clusters can be measured. In addition, size-selected clusters can be deposited on the surface and these deposited clusters can be used for investigating not only the size-selectivity of various properties, but also cluster-substrate interactions. ${ }^{14-23}$

In most previous studies of mass-selected clusters deposited on surfaces, clusters with only one specific size could be deposited at once. ${ }^{18-23}$ The preparation of samples with different cluster sizes is time-consuming and the conditions of each experiment must be strictly controlled to properly study the chemical and physical properties of deposited clusters with various sizes. Here, we present a new parallel-deposition technique utilizing a Wien velocity filter, which enables deposition of clusters on a substrate with lateral separation based on their sizes. Using this technique, clusters with neighboring atomic sizes can be deposited on different places on a substrate at once, which can allow faster screening of size-selectivity of deposited clusters in diverse research fields. As an example, the parallel-deposition of $\mathrm{Au}_{n}^{+}$ $\left(n=6,7\right.$, and 8) clusters on $\mathrm{a} \mathrm{SiO}_{2} / \mathrm{Si}(100)$ surface was carried out. Among the clusters with 2-13 atoms, $\mathrm{Au}_{n}$ clusters with $n=6,7$, and 8 have been demonstrated to show pronounced even-odd alteration of oxidation behaviors on a $\mathrm{SiO}_{2} / \mathrm{Si}(100)$ surface. ${ }^{21,23}$ The effect of this previously-reported size-selectivity on the oxidation behaviors of Au clusters was re-demonstrated using the paralleldeposited $\operatorname{Au}_{n}(n=6,7$, and 8) clusters on a silica surface, proving the practicability of this new parallel-deposition technique for the size-dependent property study of mass-selected clusters.

The clusters were produced by Ar-sputtering of a gold (99.99\%) target using a magnetron sputter source. ${ }^{26}(+)$-charged Au clusters were extracted and accelerated using a $90^{\circ}$ quadrupole deflector 


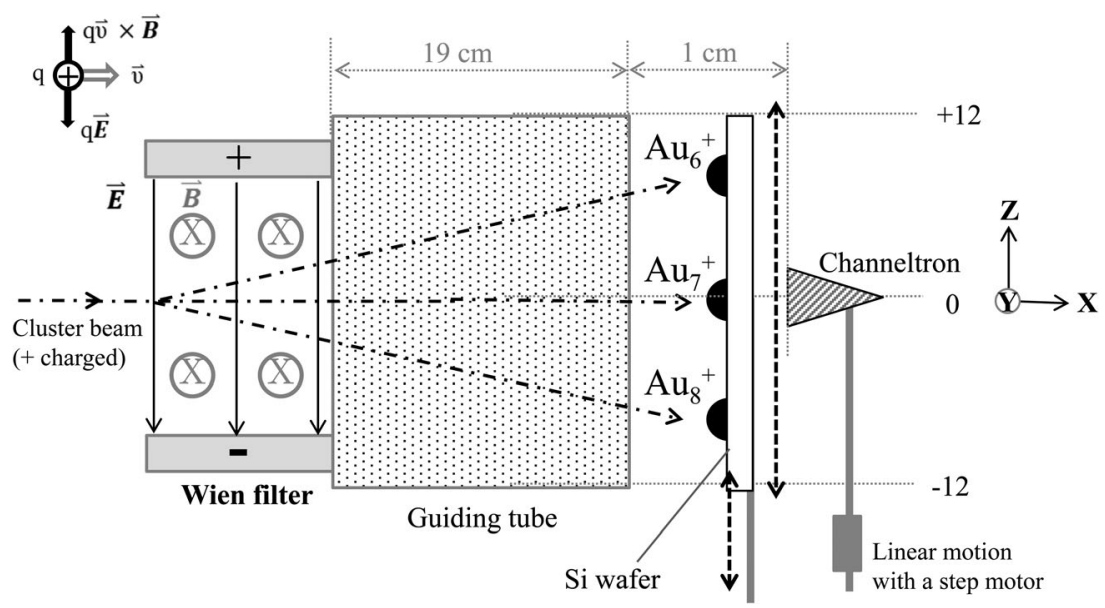

Fig. 1 The splitting of the (+)-charged cluster beam by a Wien velocity filter is schematically described using an experimental set-up of the paralleldeposition chamber. Here, the incoming cluster beam into the Wien filter with only $X$-axis velocity is assumed to consist of three different cluster sizes $(n+1, n, n-1)$ (zero $Z$-axis and $Y$-axis velocities). The center of the guiding tube (or the Wien filter) is at the zero position of the $Z$-axis. Experimental setup for the generation of the $(+)$-charged cluster ion beam is schematically shown.

with a guiding tube ( $U_{\mathrm{o}}=-1 \mathrm{kV}$, as a guiding voltage). The cluster beam was focused using Einzel lenses and its direction was corrected using electrostatic deflectors (see ESI, $\dagger$ Fig. S1). This focused $(+)$-charged cluster ion beam entered the Wien velocity filter ${ }^{25,27,28}$ and split into several cluster ion beams with various charge to mass $(q / m)$ ratios (Fig. 1$)$.

In Fig. 1, the experimental set-up used to investigate the spatial resolution of split cluster beams and their parallel deposition is schematically described. A cylinder-shaped guiding tube $\left(U_{\mathrm{o}}=1 \mathrm{kV}\right.$, a diameter of $\left.24 \mathrm{~mm}\right)$ covered by a nickel mesh (74 microns) was placed in front of the Wien filter $(\sim 0 \mathrm{~mm}$ distance along the $X$-axis) in order to reduce possible broadening of the (+)-charged cluster beam by an inhomogeneous electric field between the Wien filter and detector. The cross-section of the spread beams was checked by scanning the channeltron detector with a pin hole aperture of $\sim 0.1 \mathrm{~mm}$ along the $Z$-axis using a linear motion feedthrough with a step motor at a scanning speed of $0.1 \mathrm{~mm} \mathrm{~s}^{-1}$.

The cross-section of the beam along the $Z$-axis shown in Fig. 2 was obtained with fixed electric and magnetic fields of the Wien filter of $80 \mathrm{~V}$ across the Wien filter electrodes and $200 \mathrm{mT}$, respectively. These values of the electric and magnetic fields correspond to the maximum intensity position of the $\mathrm{Au}_{7}^{+}$clusters in the mass spectrum (see ESI, $\dagger$ Fig. S2). A sudden drop in the cluster signal from the channeltron detector was observed when its $Z$ position went beyond the size of the guiding tube (below $\sim-12 \mathrm{~mm}$ and above $\sim 12 \mathrm{~mm}$ ). The beam cross-section shown in Fig. 2 obtained by the channeltron scanning mode showed that each cluster ion beam $\left(\mathrm{Au}_{6}{ }^{+}, \mathrm{Au}_{7}{ }^{+}\right.$, and $\left.\mathrm{Au}_{8}{ }^{+}\right)$was well spatially separated along the $Z$-axis by the Wien filter. In the spatial cluster profile shown in Fig. 2, a peak corresponding to the $\mathrm{Au}_{7}{ }^{+}$cluster beam was centered at the ' 0 ' $Z$-axis position and the relative intensity of each $\mathrm{Au}_{n}{ }^{+}$cluster peak ( $n=6,7$, and 8) decreased with increasing number of $\mathrm{Au}$ atoms, which agrees with the mass spectrum shown in the ESI $\dagger$ (Fig. S2). The distance between the maximum intensities of adjacent cluster peaks was around $11 \mathrm{~mm}$.

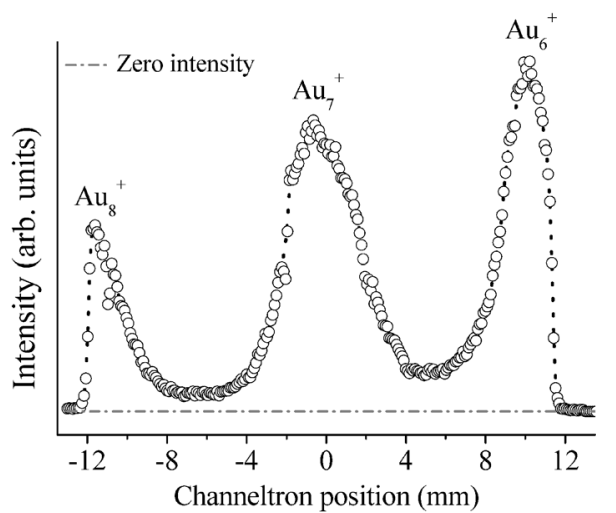

Fig. 2 The cross-section of the beam of $\mathrm{Au}_{n}{ }^{+}$clusters $(n=6,7$, and 8) after the Wien filter obtained by a channeltron detector scan along the $Z$-axis is displayed.

$\mathrm{Au}_{6}{ }^{+}, \mathrm{Au}_{7}{ }^{+}$, and $\mathrm{Au}_{8}{ }^{+}$spatially separated by the Wien filter were deposited on a $\mathrm{Si}$ wafer $\left(\mathrm{SiO}_{2} / \mathrm{Si}(100), 25 \times 15 \mathrm{~mm}\right)$ by positioning a $\mathrm{Si}$ wafer in front of the channeltron detector at

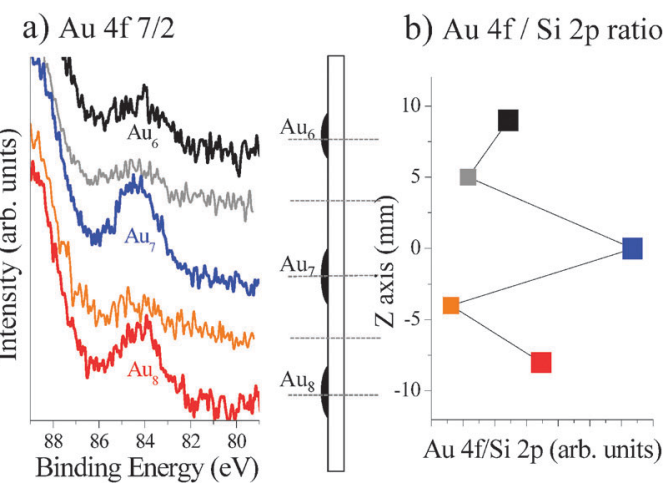

Fig. 3 (a) Au $4 f_{7 / 2}$ core-level spectra at different $Z$-axis positions are displayed. (b) The intensity ratio of $\mathrm{Au} 4 \mathrm{f}_{7 / 2}$ with respect to the $\mathrm{Si} 2 \mathrm{p}$ core-level XPS spectra at each Z-axis position is shown. 
the center of the guiding tube (Fig. 1). The $\mathrm{Si}$ wafer was chemically etched with an acidic solution containing $\mathrm{H}_{3} \mathrm{PO}_{4}$, $\mathrm{HNO}_{3}, \mathrm{CH}_{3} \mathrm{COOH}$, and $\mathrm{H}_{2} \mathrm{O}$ at a volume ratio of $3: 3: 23: 1$ before deposition to immobilize the deposited Au clusters. ${ }^{21,23}$ Size-selected $\mathrm{Au}_{n}{ }^{+}$clusters were soft-landed on the $\mathrm{SiO}_{2} / \mathrm{Si}$ surface with a kinetic energy of less than $\sim 0.2 \mathrm{eV}$ per atom by applying a de-acceleration voltage on the substrate. Clusters were deposited on the Si wafer with a cluster current of $\sim 0.7 \mathrm{nA}$ for $40 \mathrm{~min}$ and the estimated coverage of the Au clusters on the Si wafer was $\sim 10^{13}$ clusters per $\mathrm{cm}^{2}$ (10\% of a monolayer).

Then, the sample with deposited clusters was transferred from the deposition chamber to the XPS analysis chamber (see ESI, $\dagger$ Fig. S3) in order to evaluate the lateral separation of deposited clusters on the surface. The spatial resolution of our XPS system was checked with Au foil with a lateral size of $2 \times 20 \mathrm{~mm}$ and was found to be less than $\sim 3 \mathrm{~mm}$ (see ESI, $\dagger$ Fig. S4). XPS spectra at different $Z$-positions were obtained in order to check the position of each cluster spot and spatial separation between neighboring spots (Fig. 3).

The intensity of the Au4f core-level XPS spectra increased and decreased when the sample was laterally scanned along the $Z$-axis, showing three discrete spots of $\mathrm{Au}$ clusters $\left(\mathrm{Au}_{6}, \mathrm{Au}_{7}\right.$, and $\mathrm{Au}_{8}$ clusters at $\sim 9,0$, and $-8 \mathrm{~mm}$, respectively). Fig. 3 shows the intensity ratio of the Au4f to Si 2p core-level XPS spectra recorded at 5 different positions along the $Z$-axis, corresponding to the center of $\mathrm{Au}_{6}$, between $\mathrm{Au}_{6}$ and $\mathrm{Au}_{7}$, the

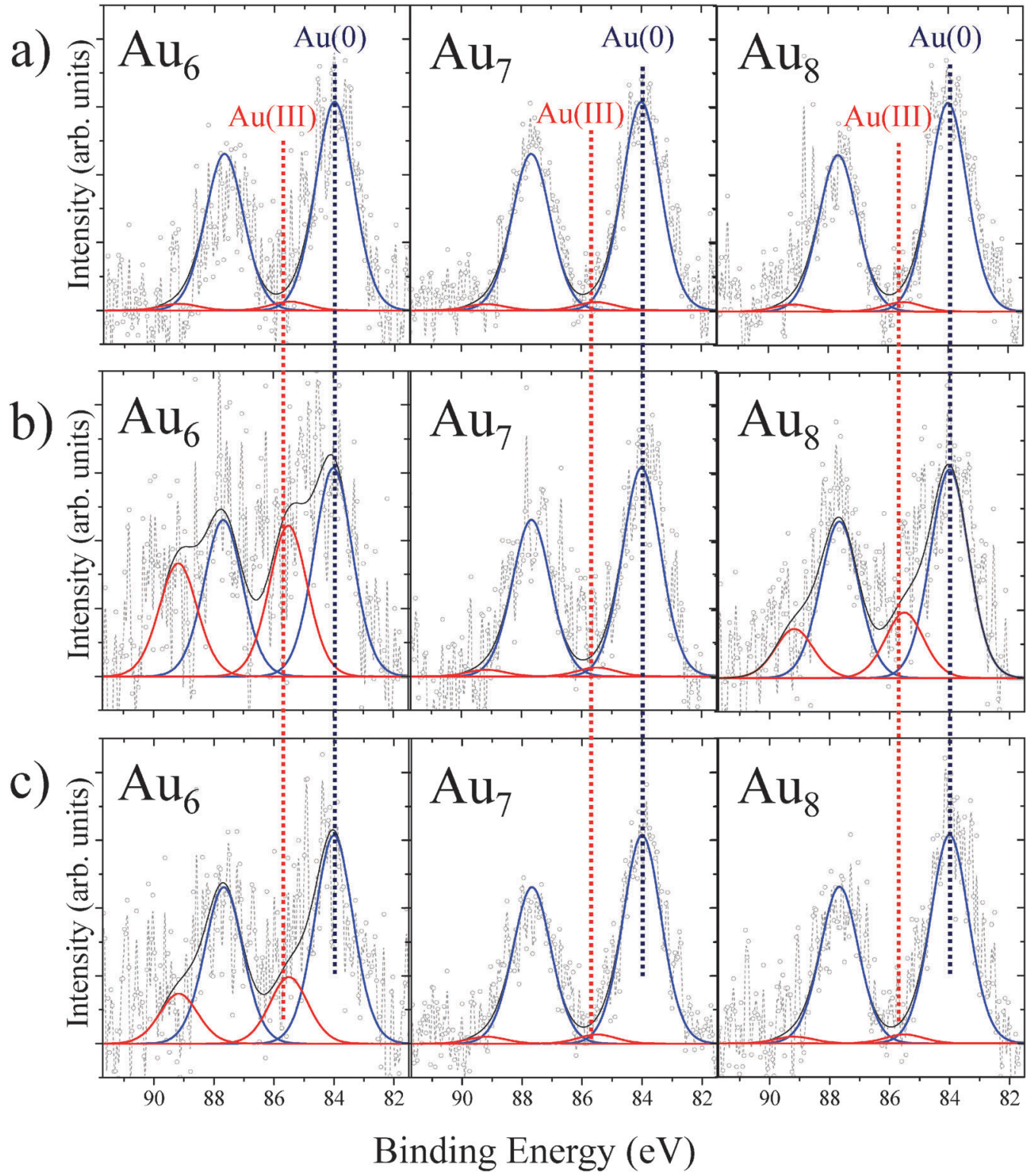

Fig. 4 (a) Au 4 f core-level XPS spectra of the as-prepared sample recorded at different $Z$-axis positions corresponding to the centers of the three spots of the $\mathrm{Au}_{6}, \mathrm{Au}_{7}$, and $\mathrm{Au}_{8}$ clusters are shown. (b) Au $4 \mathrm{f}$ core-level XPS spectra of the sample after $\mathrm{O}_{2}$ exposure $\left(8.0 \times 10^{-5} \mathrm{Torr} \mathrm{O}_{2}\right.$ for $1 \mathrm{hr}$ with a hot Pt filament) are shown. (c) The Au $4 \mathrm{f}$ core-level XPS spectra of the sample after subsequent $\mathrm{CO}(6000 \mathrm{~L})$ exposure at room temperature are shown. Each spectrum was normalized by the intensity of each $\mathrm{Au}(0)$ state for comparison. 
center of $\mathrm{Au}_{7}$, between $\mathrm{Au}_{7}$ and $\mathrm{Au}_{8}$, and the center of $\mathrm{Au}_{8}$ (from top to bottom). Each $\mathrm{Au}_{4 \mathrm{f}_{7 / 2}}$ peak $\left(\mathrm{Au}_{6}, \mathrm{Au}_{7}\right.$, and $\left.\mathrm{Au}_{8}\right)$ was centered at $\sim 84 \mathrm{eV}$, corresponding to $\mathrm{Au}(0){ }^{21}$

The exact positions of each spot of the $\mathrm{Au}_{n}$ clusters $(n=6,7$, and 8) along the $Z$-axis probed by XPS after deposition shown in Fig. 3 were not exactly the same as those determined by channeltron scanning shown in Fig. 2. This is probably due to differences in the experimental conditions where the drift distance of cluster beams along the $X$-axis from the end of the guiding tube to the substrate was shorter than that for the detector (Fig. 1). Also, an additional de-acceleration voltage was applied on the substrate only during deposition for softlanding.

Concerning the limitations of the technique, the spatial resolution would in principle correspond to the mass resolution of the Wien filter. In this case, the upper limit of the Au cluster size which can be parallel deposited with a spatial separation with neighboring clusters would be $\sim n=20$. However, when we measured the spot size on the sample using XPS and compared it to the diameter of the ion beam for a single mass, we found a spot size of $5 \mathrm{~mm}$ for deposited $\mathrm{Au}_{6}{ }^{-}$, while the diameter of the ion beam was $3 \mathrm{~mm}$. Hence, there is a broadening caused by the soft landing process, which reduces the mass resolution for the deposited clusters down to 10. If there would be more space for the ion beam in the Wien filter, a larger spread between the different beams corresponding to different masses would be found, making parallel deposition of larger clusters with spatial separation possible.

Spatial separation of adjacent cluster spots was observed after the cluster deposition and more importantly, sizedependent behaviors of parallel-deposited $\mathrm{Au}_{n}(n=6,7$, and 8) clusters were also observed, which will be presented below.

Oxidation behaviours of parallel-deposited $\mathrm{Au}_{n}(n=6-8)$ clusters on a $\mathrm{SiO}_{2} / \mathrm{Si}$ surface were evaluated using an in situ XPS set-up in order to prove the feasibility of the paralleldeposition technique to study size-dependent properties (see ESI, $\dagger$ Fig. S3). These particular series of $\mathrm{Au}$ clusters were chosen, since their even-odd oxidation behaviors have been already well established by previous studies. ${ }^{21,23}$ The sample surface of parallel-deposited $\mathrm{Au}_{n}$ clusters $(n=6,7$, and 8) was exposed to oxygen $\left(8.0 \times 10^{-5}\right.$ Torr $)$ activated by a hot Pt filament (4.5 A) for $1 \mathrm{~h}$ in the preparation chamber. Then, the sample was subsequently exposed to a CO atmosphere (6000 Langmuir) in the preparation chamber. After exposure to each gas, XPS spectra were recorded in the main chamber at different $Z$ positions corresponding to the $\mathrm{Au}_{6}, \mathrm{Au}_{7}$, and $\mathrm{Au}_{8}$ clusters. No changes in the lateral separation on the $\mathrm{SiO}_{2} / \mathrm{Si}$ surface were observed even after $6 \mathrm{~h}$ of $\mathrm{O}_{2}$ exposure.

In Fig. 4, the Au4f core-level spectra before gas exposure, after $\mathrm{O}_{2}$ exposure, and after $\mathrm{CO}$ exposure at each $Z$ position for the $\mathrm{Au}_{6}, \mathrm{Au}_{7}$, and $\mathrm{Au}_{8}$ clusters are displayed after Si satellite subtraction. Each Au 4 f peak was deconvoluted using linearlymixed Gaussian-Lorentzian functions with a fixed binding energy and full-width at half-maximum.

Oxidized $\mathrm{Au}$ states (Au(III)) appeared in the Au 4f XPS spectra of the even-numbered $\mathrm{Au}_{n}$ clusters ( $n=6$ and 8) upon $\mathrm{O}_{2}$ exposure, whereas odd-numbered $\mathrm{Au}_{7}$ did not show any discernable change under the same conditions. The oxidized states of the $\mathrm{Au}_{6}$ and $\mathrm{Au}_{8}$ clusters were reduced by subsequent CO exposure (6000 Langmuir) at room temperature. The previously reported even-odd oxidation pattern of $\mathrm{Au}_{n}(n=6-8)$ on a silica surface ${ }^{21,23}$ was reproduced by our experimental results, where the unique properties of $\mathrm{Au}_{6}, \mathrm{Au}_{7}$, and $\mathrm{Au}_{8}$ can be found on different places in one sample. It is also worth mentioning that the even-odd oxidation behaviors of $\mathrm{Au}_{n}$ clusters $(n=6$, 7, and 8) parallel-deposited on a silica surface were seen even with Pt contamination $(\sim 1.5$ at $\%)$ during oxygen exposure.

In summary, we present a new parallel-deposition technique, in which clusters can be spatially separated by their masses and simultaneously deposited on one substrate. By utilizing a Wien velocity filter, the spatial separation of differently sized clusters from non-size-selected cluster ion beams was achieved. The cross-section of the spread beams after passing the Wien filter was investigated by scanning a channeltron detector and the spatial resolution of the deposited clusters was also confirmed by XPS analysis. The previously reported even-odd oxidation pattern of Au clusters was reproduced using parallel-deposited $\mathrm{Au}_{n}$ clusters $(n=6,7$, and 8$)$ on a silica surface, demonstrating the potential of this new parallel-deposition technique for studying various size-dependent properties of clusters.

\section{Acknowledgements}

Financial support is gratefully acknowledged from the German Research Foundation (DFG), Grant-No. GA 389/20-1 "Paralleldeposition von Clusterionen". We thank the machine shop team at the University of Konstanz for the fabrication of major parts of our cluster deposition setup and of course, the Wien filter.

\section{Notes and references}

1 Y. Volokitin, J. Sinzig, L. J. de Jongh, G. Schmid, M. N. Vargaftik and I. I. Moiseevi, Nature, 1996, 384, 621-623.

2 M.-C. Daniel and D. Astruc, Chem. Rev., 2004, 104, 293-346.

3 Y. Wang and N. Herron, J. Phys. Chem., 1991, 95, 525-532.

4 C. A. Foss, G. L. Hornyak, J. A. Stockert and C. R. Martin, J. Phys. Chem., 1994, 98, 2963-2971.

5 A. Hagfeldt and M. Graetzel, Chem. Rev., 1995, 95, 49-68.

6 C. J. Murphy, T. K. Sau, A. M. Gole, C. J. Orendorff, J. Gao, L. Gou, S. E. Hunyadi and T. Li, J. Phys. Chem. B, 2005, 109, 13857-13870.

7 S. Mandal, J. Wang, R. E. Winans, L. Jensen and A. Sen, J. Phys. Chem. C, 2013, 117, 6741-6746.

8 W.-N. Wang, W.-J. An, B. Ramalingam, S. Mukherjee, D. M. Niedzwiedzki, S. Gangopadhyay and P. Biswas, J. Am. Chem. Soc., 2012, 134, 11276-11281.

9 R. C. Jeff, M. Yun, B. Ramalingam, B. Lee, V. Misra, G. Triplett and S. Gangopadhyay, Appl. Phys. Lett., 2011, 99, 072104.

10 M. Haruta, N. Yamada, T. Kobayashi and S. Iijima, J. Catal., 1989, 115, 301-309.

11 M. Haruta, S. Tsubota, T. Kobayashi, H. Kageyama, M. J. Genet and B. Delmon, J. Catal., 1993, 144, 175-192. 
12 M. Valden, X. Lai and D. W. Goodman, Science, 1998, 281, 1647-1650.

13 A. Cho, Science, 2003, 299, 1684-1685.

14 W. A. de Heer, Rev. Mod. Phys., 1993, 65, 611-676.

15 S. N. Khanna and P. Jena, Phys. Rev. B: Condens. Matter Mater. Phys., 1995, 51, 13705-13716.

16 I. M. L. Billas, A. Châtelain and W. A. de Heer, Science, 1994, 265, 1682-1684.

17 H. Wu, S. R. Desai and L.-S. Wang, Phys. Rev. Lett., 1996, 76, 212-215.

18 A. Sanchez, S. Abbet, U. Heiz, W. D. Schneider, H. Häkkinen, R. N. Barnett and U. Landman, J. Phys. Chem. A, 1999, 103, 9573-9578.

19 S. Lee, C. Fan, T. Wu and S. L. Anderson, J. Am. Chem. Soc., 2004, 126, 5682-5683.

20 Y. Watanabe, X. Wu, H. Hirata and N. Isomura, Catal. Sci. Technol., 2011, 1, 1490-1495.
21 D. C. Lim, R. Dietsche, M. Bubek, G. Ganteför and Y. D. Kim, ChemPhysChem, 2006, 7, 1909-1911.

22 D. C. Lim, R. Dietsche, M. Bubek, T. Ketterer, G. Gantefor and Y. D. Kim, Chem. Phys. Lett., 2007, 439, 364-368.

23 D. C. Lim, R. Dietsche, G. Ganteför and Y. D. Kim, Appl. Surf. Sci., 2009, 256, 1148-1151.

24 V. N. Popok, I. Barke, E. E. B. Campbell and K.-H. MeiwesBroer, Surf. Sci. Rep., 2011, 66, 347-377.

25 S. G. Hall, M. B. Nielsen, A. W. Robinson and R. E. Palmer, Rev. Sci. Instrum., 1997, 68, 3335-3339.

26 H. Haberland, M. Karrais and M. Mall, Z. Phys. D: At., Mol. Clusters, 1991, 20, 413-415.

27 M. Schmidt, H. Peng, G. Zschornack and S. Sykora, Rev. Sci. Instrum., 2009, 80, 063301.

28 B. Wrenger and K. H. Meiwes-Broer, Rev. Sci. Instrum., 1997, 68, 2027-2030. 